\title{
Electro-Deposition of Cu on Open Cell Aluminum Foams
}

\author{
A. Antenucci, S. Guarino, V. Tagliaferri, N. Ucciardello
}

Department of Business Engineering, University of Rome "Tor Vergata”, Rome, Italy.

Email: nadia.ucciardello@uniroma2.it

Received September $2^{\text {nd }}, 2013$; revised October $11^{\text {th }}, 2013$; accepted October $28^{\text {th }}, 2013$

Copyright (C) 2013 A. Antenucci et al. This is an open access article distributed under the Creative Commons Attribution License, which permits unrestricted use, distribution, and reproduction in any medium, provided the original work is properly cited.

\begin{abstract}
This manuscript deals with the electro-deposition of $\mathrm{Cu}$ on aluminum foams. Metallic foams are highly porous materials which present complex structure of three-dimensional open cells. This aspect causes strong limitations in mass transport due to electro-deposition technology. Experimental tests were performed to study the influence of the operational parameters on the overall performance of the coated aluminum foams. The experimental findings revealed that the manufactured metal foams were characterized by a high thermal conductivity and low process costs, making these materials very promising in many technological fields. On the basis of the experimental results, analytical models are proposed to predict the quantity and the quality characteristics of the coating.
\end{abstract}

Keywords: Electro-Deposition; Open Cell Aluminum Foams; Copper

\section{Introduction}

Aluminum foams are a recent class of materials for their characteristics have been stimulating great interest in many technological domains. Metal foams possess a light weight and can absorb high impact energies, and they are very efficient vibration damping and are very suitable for thermal exchange applications. These properties make them suitable for a wide range of industrial applications [1]. In the last years, many researchers have studied aluminum foams, but the knowledge in the field of the manufacturing and the subsequent transformation processes is still very poor [1-4]. Many studies have been made in the field of aluminum foams, much less for other metals such as copper, steel, nickel, etc. [1,3]. In addition to the lack of knowledge, the production of foams, by using other metals that are not aluminum, is still characterized by industrially unacceptable costs [1]. In this context, this paper intends to propose an alternative process to the bulk ones in which copper foams are obtained by electro-deposition. In this paper the copper electrodeposition was studied in order to improve the thermal properties of the aluminum foams used for heat exchanger applications. In literature there are many studies of electro-deposition [5] but the information about the deposition of copper on aluminum, in particular aluminum foams, is very poor. Electro-deposition is a very versatile technique for the coating of mainly metallic substrates [5]. It can even be applied on very complex geometries [5-8]. The open cell metal foams, which were employed in this study, were produced by the method of replication of polymeric patterns [1]. Open cell metal foams have a very complex structure. This aspect causes strong limitations in mass transport due to electro-deposition technology [5]. In this paper, experimental tests were performed to study the influence of the operational parameters of electro-deposition process on the overall performance of the coated aluminum foams. Hence, for an almost homogeneous coating, two electro-deposition technologies were improved. On the basis of the experimental findings, an analytical model is proposed with the aim to predict the quantity and the quality characteristics of the coating. The experimental findings revealed that the manufactured metal foams were characterized by a high thermal conductivity and low process costs, making these materials very promising in many technological fields.

\section{Experimental Procedure}

Aluminum foam was produced by the method of replication of polymeric pattern, with a porosity of $10 \mathrm{ppi}$. All the samples were manufactured with the same shape $(20 \times 20 \times 50 \mathrm{~mm})$. However, the density varies quite significantly from one sample to another, on equal pore size, changing from $150 \mathrm{~kg} / \mathrm{m}^{3}$ to $250 \mathrm{~kg} / \mathrm{m}^{3}$, much lower 
than the density of the base material $\left(2700 \mathrm{~kg} / \mathrm{m}^{3}\right)$. The electro-deposition was carried out in an electrolytic cell at $25^{\circ} \mathrm{C}$. The electrolyte consisted of $1.25 \mathrm{M} \mathrm{CuSO}_{4}, 0.61$ $\mathrm{M} \mathrm{H}_{2} \mathrm{SO}_{4}$ and $\mathrm{Cl}^{-} 50 \mathrm{ppm}$. The bath was kept in agitation with a magnetic agitator, located inside the electrolytic cell. The influence of the magnitude of the agitation was studied in a previous phase of the experimentation, and the results leaded to choose $3.5 \mathrm{rpm}$ for this parameter. The consumable copper anode has been designed and manufactured in such a way that it can be adapted to the shape of the foam, obtaining the best possible result. The shape is that of a hollow tubular, whose dimensions are $50 \times 30 \times 5 \mathrm{~mm}$ (Figure 1). The foam (cathode), connected to the terminal of the current generator, was put in the anode and immersed in the electrolyte for only 40 $\mathrm{mm}$ in height. The range of variation of current was imposed from $1.5 \mathrm{~A}$ to $3.5 \mathrm{~A}$, while time's range was imposed from $9 \times 10^{2}$ to $1.25 \times 10^{4}$ seconds. On each samples was leaded an image analysis through optical microscope and scanning electron microscope (SEM).

\section{Theoretical Model}

The $\mathrm{P} \%$ was chosen as the principal parameter for assessing the effectiveness of the electro-deposition, of course combined with microscope observations, and to predict the quantity of deposited copper.

It's calculated as:

$$
P \%=\left[\left(P_{2}\right)_{i}-\left(P_{1}\right)_{i}\right] /\left(P_{1}\right)_{i}
$$

where the subscript $i$ indicates that the quantities referred to are related only to the portion of foam immersed (thus only to the one that actually participates to the deposition). The mass of copper deposited appears in the numerator, while the denominator is always the mass of

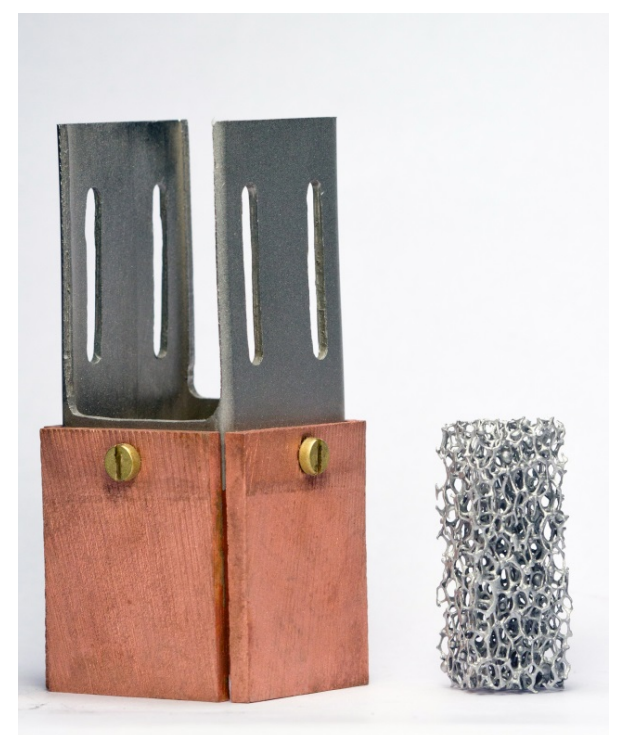

Figure 1. The copper anode and the aluminum foam. the specimen before the electro-deposition (obviously, it is a constant once fixed the immersed volume). So we can write that:

$$
P \%=\mathrm{M}_{\mathrm{Cu}} /\left(\rho * V_{i}\right)=\left(\mathrm{MM}_{\mathrm{Cu}} * \mathrm{n}_{\mathrm{Cu}}\right) /\left(\rho * V_{i}\right)
$$

where $\mathrm{MM}_{\mathrm{Cu}}$ is the molar mass of copper and $\mathrm{n}_{\mathrm{Cu}}$ is the number of moles of copper. Called e the electric charge of an electron, $t$ the time, $i$ the electric current and $\mathrm{Na}$ Avogadro's number we can write:

$$
\begin{aligned}
P \% & =\left[\mathrm{MM}_{\mathrm{Cu}} /\left(N_{a} * 2 * e\right)\right] *\left[(i * t) /\left(\rho * V_{i}\right)\right] \\
P \% & =3.297 \times 10^{-7} *\left[(i * t) /\left(\rho * V_{i}\right)\right]
\end{aligned}
$$

There is therefore a relationship of direct proportionality between the amount of copper deposited and the current or the time. To control the quality of the cupric film, two models were formulated using two different parameters that contain the variables that come into play in the process. The first parameter taken into consideration was

$$
\mathrm{K}_{1}=(i / \rho)^{*}
$$

Thus it is assumed a model in which the goodness of the coating is directly proportional to the intensity of electric current and inversely proportional to the density of the foam. In the second optimization method was chosen the parameter

$$
\mathrm{K}_{2}=\left(i /\left(\rho * V_{i}\right)\right)^{*}
$$

that is different from $K_{1}$ for the presence, in the denominator, of the immersed volume of the foam. Both $\mathrm{K}_{1}$ and $\mathrm{K}_{2}$ were calculated using the values obtained from the sample which had been recognized as the best in terms of homogeneity of the coating. They assume respectively the values of $1.16 \times 10^{-2} \mathrm{~A} * \mathrm{~m}^{2} / \mathrm{Kg}$, and $829.58 \mathrm{~A} / \mathrm{Kg}$. The other parameters could be calculated, with a method or the other, using respectively the systems:

$$
\begin{aligned}
& i=\mathrm{K}_{1} * \rho \\
& t=\left[1 /\left(3.297 \times 10^{-7}\right)\right] *(P \%)^{*} *\left(1 / \mathrm{K}_{1}\right) * V_{i}
\end{aligned}
$$

and

$$
\begin{aligned}
& i=\mathrm{K}_{2} * \rho * V_{i} \\
& t=\left[1 /\left(3.297 \times 10^{-7}\right)\right] *(P \%)^{*} *\left(1 / \mathrm{K}_{2}\right)
\end{aligned}
$$

\section{Results}

The validation of the electro-deposition model was done on all the samples obtained during the tests (Figure 2). Interpolating the experimental points, the slope of the linear regression $\left(R^{2}=0.9967\right)$ is equal to $3.330 \times 10^{-5}$ $\mathrm{Kg}(\mathrm{A} * \mathrm{~s})$ that is very close to the theoretical one of 3.297 $\times 10^{-5} \mathrm{Kg}(\mathrm{A} * \mathrm{~s})$ : is the evidence that the model is valid and therefore can be used as a tool for prediction. The image analysis, leaded on all the samples with optical 


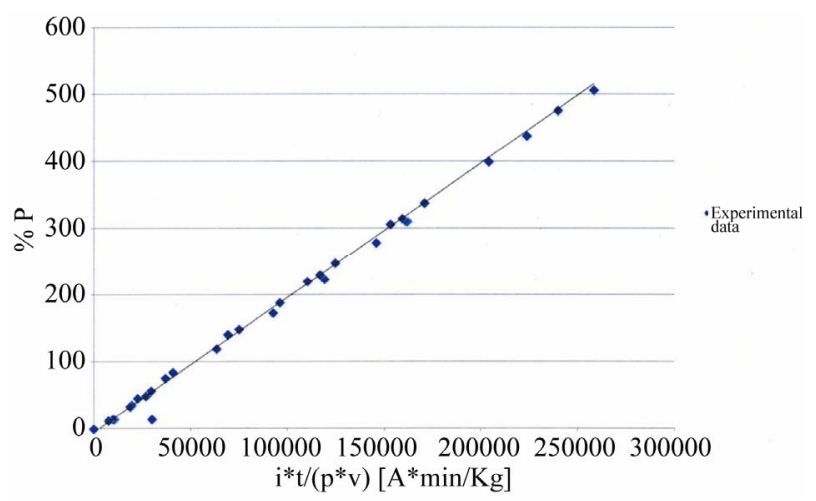

Figure 2. Validation of the electro-deposition model.

microscope and SEM, showed that the more $\mathrm{P} \%$ is large, the more the sample is well covered. However, was noted that using high values of DC current causes a preferential deposition of copper on the external sides of the foams, instead of the inner part, with the formation of copper excrescences on the edges. An optimal value of current was found in $2.3 \mathrm{~A}$. For the first method of optimization, was used a specimen with a density of $196 \mathrm{~kg} / \mathrm{m}^{3} \mathrm{im}-$ mersed for a volume of $1.86 \times 10^{4} \mathrm{~mm}^{3}$ approximately. From these data derives that the deposition conditions were $3.14 \mathrm{~A}$ and $1.062 \times 10^{4} \mathrm{~s}$. The image analysis shows that there is a good covering either in terms of extension and uniformity of thickness: the not covered areas within the foam are very limited in number and amplitude (Figure 3). For the second method of optimization, was used a specimen with a density of $147 \mathrm{~kg} / \mathrm{m}^{3}$ immersed for a volume of $1.25 \times 10^{4} \mathrm{~mm}^{3}$. The current calculated was $1.5 \mathrm{~A}$ for $1.47 \times 10^{4} \mathrm{~s}$ (Figure 4).

The results obtained this way are very close to those of the previous optimization test. Below, was reported a SEM image of the cupric coating obtained after optimization.

\section{Conclusion}

In this study was electrodeposited copper on open cell aluminum foams. A model of deposition was proposed and validated, and was found an optimum in terms of DC current and agitation in $2.3 \mathrm{~A}$ and $3.5 \mathrm{rmp}$ to set in the electro-deposition process. Higher values of these parameters lead to worse results. Two models of optimization were also studied, obtaining thick and continuous coating upon the samples, reducing almost completely uncovered areas within the foams. Referring to the considered foams, they were imposed $3.14 \mathrm{~A}$ and $1.062 \times 10^{4} \mathrm{~s}$ in the first method, $1.5 \mathrm{~A}$ and $1.47 \times 10^{4} \mathrm{~s}$ in the second one.

\section{Acknowledgements}

Highly qualified and continuous technical assistance with
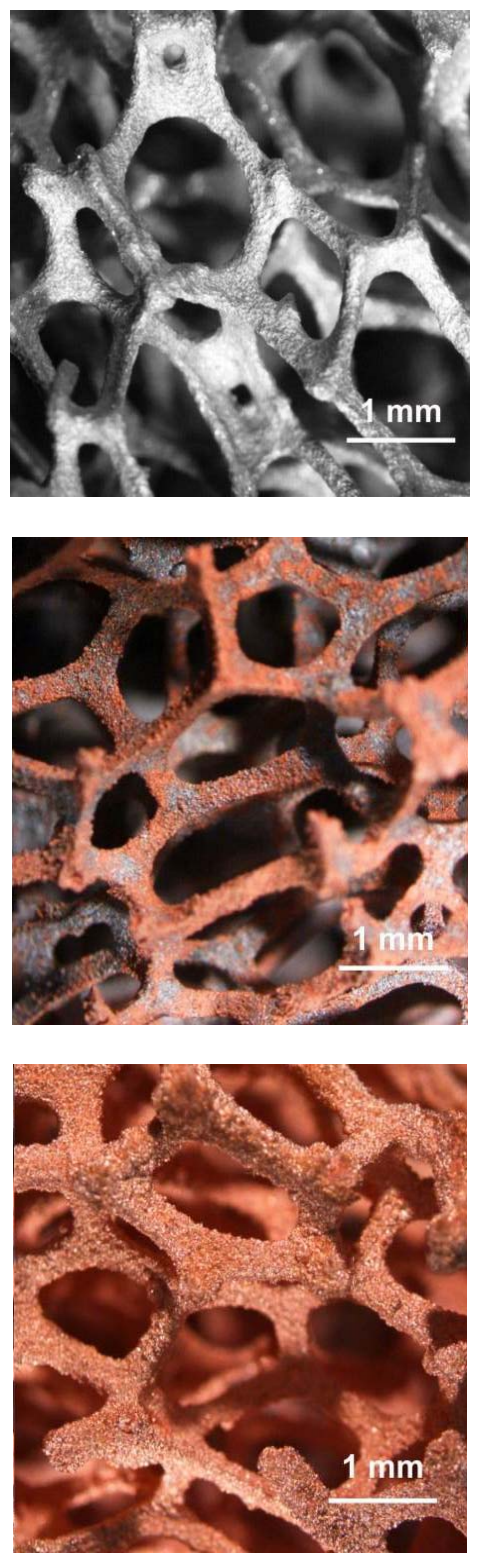

Figure 3. Stereoscopic microscope image analysis $(I=3.14$ $\left.A ; t=1.062 \times 10^{4} s\right)$.

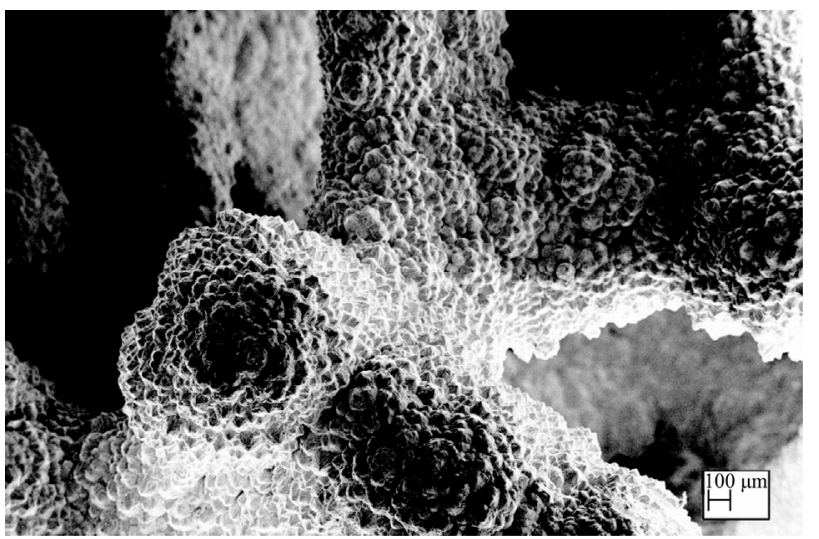

Figure 4. SEM image $\left(\mathrm{I}=1.5 \mathrm{~A} ; \mathrm{t}=1.47 \times 10^{4} \mathrm{~s}\right)$. 
all the experiments described in this paper is kindly acknowledged to Massimiliano Della Millia, Dipartimento di Ingegneria Industriale, Università di Roma Tor Vergata.

\section{REFERENCES}

[1] H. P. Degischer and B. Kriszt, "Handbook of Cellular Metals: Production, Processing and Applications," WileyVCH Verlag GmbH \& Co., 2002. http://dx.doi.org/10.1002/3527600558

[2] S. Guarino, M. Barletta, S. Pezzola and S. Vesco, "Manufacturing of Steel Foams by Slip Reaction. Foam Sintering (SRFS)," Materials and Design, Vol. 40, 2012, pp. 268-275. http://dx.doi.org/10.1016/j.matdes.2012.03.022

[3] M. Barletta, A. Gisario, S. Guarino and G. Rubino, "Production of Open Cell Aluminum Foams by Using the Dissolution and Sintering Process (DSP)," Journal of Manufacturing Science and Engineering, Vol. 131, No. 4, 2009, pp. 1087-1357. http://dx.doi.org/10.1115/1.3159044
[4] G. Costanza, G. Gusmano, R. Montanari, M. E. Tata and N. Ucciardello, "Effect of Powder Mix Composition on Al Foam Morphology," Journal of Materials: Design and Applications, Vol. 2, 2008, pp. 131-140.

[5] M. W. Losey and J. J. Kelly, "Electro-Deposition," Comprehensive Microsystems, Vol. 1, 2008, pp. 271-292. http://dx.doi.org/10.1016/B978-044452190-3.00010-0

[6] A. Jung, H. Natter, R. Hempelmann, S. Diebels, M. R. Koblischka, U. Hartmann and E. Lach, "Nanocrystalline Alumina Dispersed in Nanocrystalline Nickel: Enhanced Mechanical Properties," Journal of Materials Science, Vol. 44, No. 11, 2011, pp. 2725-2735. http://dx.doi.org/10.1007/s10853-009-3330-1

[7] M. Schlesinger and M. Paunovic, "Modern Electroplating," Wiley, New York, 2000.

[8] A. Radisic, J. G. Long, P. M. Hoffmann and P. C. Searson, "Nucleation and Growth of Copper on TiN from Pyrophosphate Solution," Journal of the Electrochemical Society, Vol. 148, No. 1, 2001, pp. C41-C46. http://dx.doi.org/10.1149/1.1344539 